\title{
ALLOCHARES AZUREUS: AN UNUSUAL WASP EXPLOITS UNUSUAL PREY (HYMENOPTERA: POMPILIDAE; ARACHNIDA: FILISTATIDAE)
}

\author{
By Mark Deyrup', James T. Cronin ${ }^{1}$, and \\ Frank E. KurCZEWSKI ${ }^{2}$
}

The spider wasp genus Allochares includes a single species, $A$. azureus (Cresson), occurring across the extreme southern U.S. from Florida to California, and southward to the Mexican states of Vera Cruz and Jalisco (Evans 1951). This species shows, for a pompilid, unusual morphological simplicity and nudity. The legs are almost spineless, the body is devoid of erect hairs, and the mandibles lack setae. The tarsal claws, unlike those of other pompilids, are almost straight, widened dorsoventrally, and flattened below (Fig. 1A). The head is strongly convex in front and somewhat concave behind, and the pronotum is rather long (Evans 1951, 1966a) (Fig. 1C). Adults have been collected on flowers of Baccharis and Solidago (Evans 1951); otherwise, nothing is known of the biology of $A$. azureus.

At the Archbold Biological Station (Highlands Co., Florida), $A$. azureus was first seen around buildings. A recent 3-year Malaise trap study of scrub insects at the Station produced no specimens of $A$. azureus, indicating that this wasp might be associated with domestic spiders. This suspicion was confirmed in the summer of 1987, when we observed $A$. azureus hunting a species of hackled band spider, Filistata hibernalis Hentz, found in dark, confined places, such as the inside of open sheds. We realized then that $A$. azureus was probably amenable to laboratory and field study.

\section{MATerials AND MethodS}

Filistata hibernalis, collected from the buildings of the Archbold Biological Station, were established in $30 \times 30 \times 30 \mathrm{~cm}$ screened cages. From one to four spiders eventually occupied each cage

\footnotetext{
'Archbold Biological Station, P.O. Box 2057, Lake Placid, FL 33852. Correspondence to Mark Deyrup.

2State University of New York, College of Environmental Science and Forestry, Syracuse, NY 13210.

Manuscript received by the editor October 7, 1988.
} 

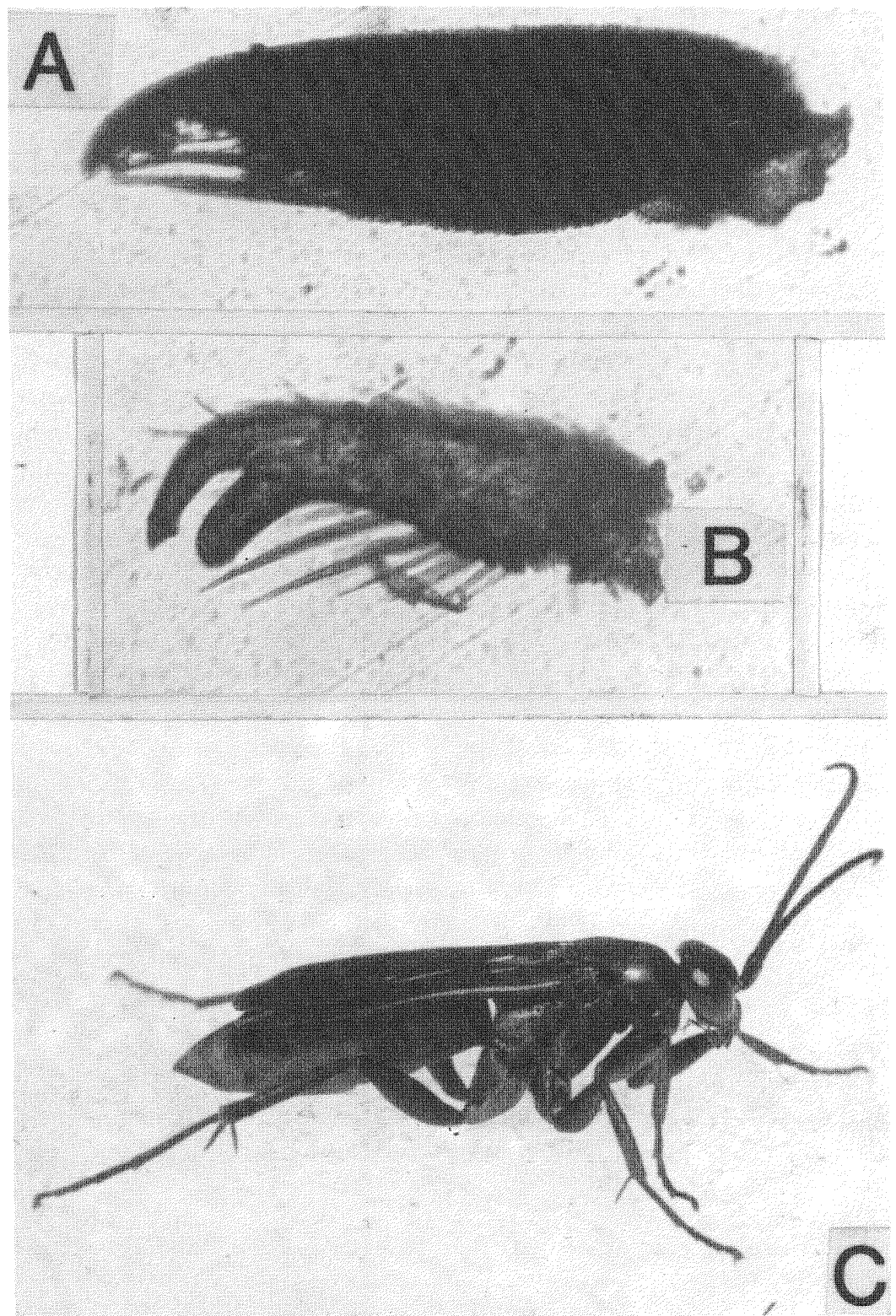

Fig. 1. A, Claw of Allochares azureus; B, claw of Episyron conterminus; C, A. azureus, female. 
before we introduced the wasps. Vertical cardboard strips, $4 \mathrm{~cm}$ wide, were placed in each of four corners of the cages, extending from top to bottom of the cages. The placement of the strips produced artificial crevices about $1 \mathrm{~cm}$ deep between the cardboard and the screening. Most of the spiders spun webs with retreats between the screening and the cardboard, so the behavior of the spider and the hunting wasp could be observed easily. Additional spiders were introduced into cages to replace those taken by the wasps, and these spiders readily occupied vacated webs. Spiders were provided various insect prey, chiefly tabanids. Five female A. azureus were collected as they hunted $F$. hibernalis around buildings and introduced singly into the cages. Additional wasps were reared in the laboratory. We observed more than 50 hunting sequences, both in the field and in the laboratory. Once parasitized, most spiders were removed from their cages and placed in vials, although a few were left in the cages. Male wasps were collected outdoors as they were attracted to cages containing virgin females. When wasps emerged from their cocoons in the laboratory, they were usually placed in a cage with a member of the opposite sex. Females were later admitted into cages containing spiders. Spiders and wasps were kept at $24^{\circ} \mathrm{C}$. A honey-water solution was provided ad libitum as nourishment for the caged wasps.

\section{Hunting Behavior}

F. hibernalis builds its web (Fig. 2A) in cracks and recesses in sheltered sites, and it is in such places that we observed $A$. azureus hunting outdoors. Because $A$. azureus normally attacks spiders in dark, restricted places, the confines of our laboratory setup did not appear to impose too unnatural a situation on the hunting wasp. Wasp behavior in the laboratory appeared very similar to the behavior observed in the field. A. azureus hunts primarily on foot, running rapidly with the short rushes and wing-flicking typical of many pompilids. Occasional flights of a meter or less are made to new hunting spots. The wasps were sometimes tolerant of human approach, and occasionally continued hunting when we approached for close observation. Any attempt to capture a wasp was likely to cause it to fly out of sight.

When a wasp encounters a Filistata web, she pauses, orients toward the center of the web, and quickly walks into the central 


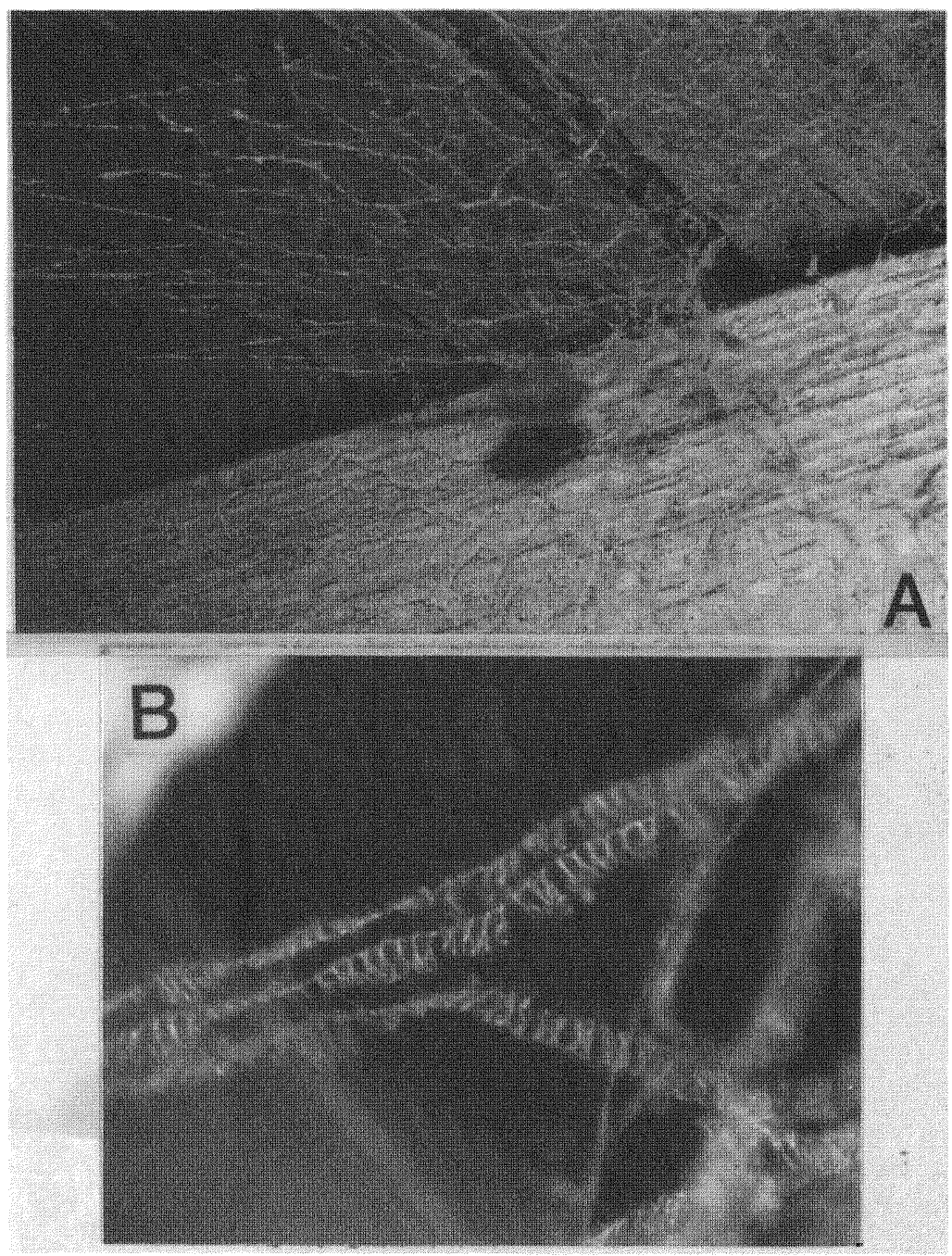

Fig. 2. A, web of $F$. hibernalis with cocoon of $A$. azureus, site is open shed; B, web of $F$. hibernalis, showing loops of Hackled bands. 
tube-like retreat (Fig. 2A). As soon as the wasp moves into the main area of the web, the spider runs rapidly out of the back of the retreat, usually leaving the web completely. If a narrow crack is available, the spider may wedge itself in, and may be able to escape from the hunting wasp. The spacing of the cardboard in the laboratory cages provided cracks wide enough to allow even the largest wasps complete access to the spiders. Spiders in these cages, when approached, leave their webs and hide in one of the cardboard cracks or in the web of another spider. Once the spider has taken up a position outside its own web, it remains completely motionless, even when closely approached by a wasp. The wasps are apparently unable to recognize a motionless spider, and on many occasions a wasp repeatedly searched the abandoned web, passing within 1-2 $\mathrm{mm}$ of its intended prey lying motionless outside the web. If the wasp actually touches a spider, the latter normally rushes away, closely pursued by the wasp. Contact with a Filistata appears to elicit in the wasp an attack response. If a wasp is captured and imprisoned in a vial, it dashes about attempting to escape, but if a Filistata has been included in the vial, the wasp stings it on first contact, and begins to drag it about the vial while seeking an exit.

Once a wasp contacts a spider, she attempts to sting it in the sternum. The movements of both wasp and spider are so rapid that we have not established an exact sequence of events. The wasp usually attacks from behind, standing on top of the spider and curving her gaster around to the venter of the spider. In some cases the spider either turns itself over or is actually flipped over by the wasp. We have never seen a frontal confrontation with the spider attempting to use its chelicerae to ward off the wasp, though the largest Filistata, when cornered, appear to stab with the front legs at the approaching wasp. The entire conflict lasts no longer than 2 or 3 seconds, and terminates abruptly when the wasp succeeds in delivering a thrust to the sternum, causing instant paralysis of the spider.

Unlike most pompilids, $A$. azureus does not bury or otherwise conceal her prey, but rather places it in the spider's own web. The web is strongly built, and its tangling hackled bands of microscopic loops remain functional for a long time without maintenance. After initial inspection of the prey, during which she may apply her mouthparts to the site of the sting, the wasp attempts to relocate the web. She may begin at once hauling the spider about by the base of 
a leg or pedipalp as she searches for the web, or she may leave the spider and make small forays. Once she has found the spider's web or the vacant web of another spider, she inspects it thoroughly, then returns to the spider. Because the spider usually drops to the ground after it has been paralyzed, it is often necessary for the wasp to drag the spider, which may be much larger than she, up vertical surfaces. Although this species of wasp lacks strongly curved tarsal claws, she seems to have no difficulty finding purchase, probably because she is supported by large tarsal pads, not only on the last tarsal segment, but on all the others as well.

The wasp may spend many minutes entangling the spider in the web, sometimes removing the spider from the web after a prolonged effort, only to begin over again. The spider is dragged into the densest part of the web, tangled extensively, and, with rapid pawing movements of one foreleg, the wasp attempts to draw loose strands over the spider. In the laboratory the wasp larva develops normally on a spider removed from the web and placed on a flat surface, but in a natural situation a spider that fell from the web would quickly be attacked by ants and other scavengers.

Before ovipisition $A$. azureus straddles the spider and makes rapid thrusting movements with the tip of her gaster along the abdomen of the spider where the egg is to be laid. The effect of these movements is to shave all the hairs from an oblong area, usually about $2 \mathrm{~mm}$ long. An egg about $1.5 \mathrm{~mm}$ long is attached to the bare spot (Fig. 3A). This bare spot allows secure attachment for the egg and provides the newly hatched larva with an initial feeding site. In many species of Pompilidae the tip of the gaster is used for such tasks as tamping soil on the burrow entrance or trowelling mud (Evans 1963); depilation of prey can now be added to the list. Depilation of a spot on the spider's abdomen may not be unique to $A$. azureus; such behavior in most other pompilids would occur in the concealment of a cell.

\section{Morphological Adaptations Associated with Hunting}

$A$. azureus has apparent morphological adaptations that suggest it has a long evolutionary association with Filistata. Compared to most other members of the Pompilini, such as species of Anoplius and Poecilopompilus, the body of Allochares is elongate and 


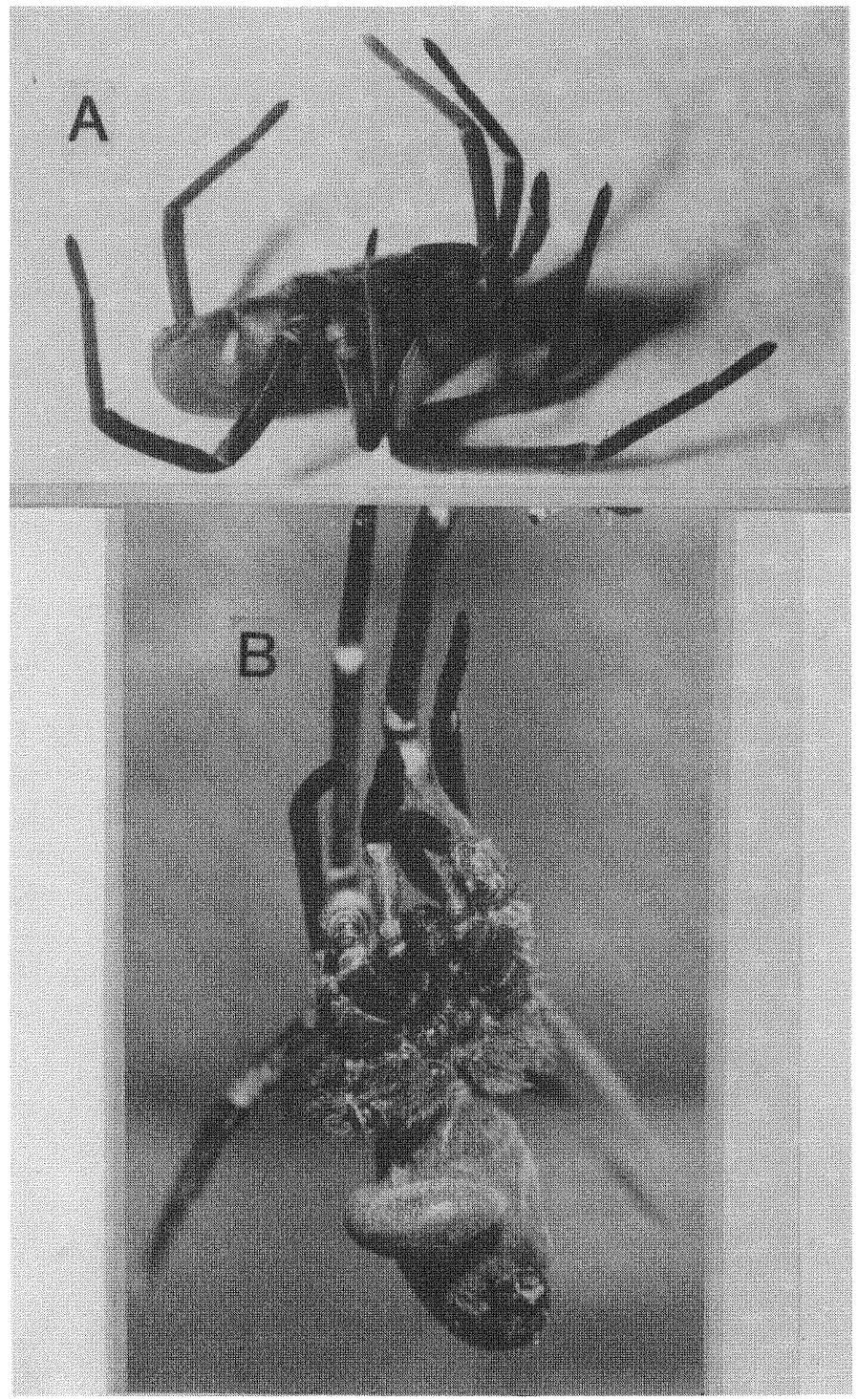

Fig. 3. A, F. hibernalis with egg of A. azureus; B, larva of $A$. azureus at 3 days. 
slightly flattened, with short, thick legs (Fig. 1C). This allows it to move about freely in narrow spaces.

The web of Filistata has strong threads of smooth silk along which are festooned masses of minute sticky loops (Fig. 2B), forming the hackled band. These loops easily entangle the appendages of most insects by becoming engaged in the hairs and tarsal claws of their legs. The hairless and spineless nature of the body and appendages of $A$. azureus may assist its progress through the hackled bands. It would seem that the absence of digging spines on the legs of Allochares, and the replacement of the prey in its own web are both dependent on the hackled band and its operation both as a trapping device for the spider and a protective barrier for the wasp larva.

The thick straight claws of Allochares (Fig. 1A) also assist in smooth movement through the hackled bands. When we placed specimens of the pompilid Episyron conterminus posterus (Fox) in the cages, their progress through the webs was slow, with frequent stops to untangle the tarsal claws. E. conterminus, which attacks orb-weaving spiders (Evans and Yoshimoto 1962), has curved and toothed claws (Fig. 1B) typical of many pompilids. $F$. hibernalis clearly recognizes the threat implied by the easy and rapid passage of $A$. azureus through its web, and vacates the web before the wasp has approached closely. No such escape response was evoked by $E$. conterminus.

\section{LaRval Development and Morphology}

The development of $A$. azureus is rapid. The egg hatches in about 3 days and the larva completes its development in 10-12 days at $24^{\circ} \mathrm{C}$. Figures $3 \mathrm{~B}, 5 \mathrm{~A}$, and $5 \mathrm{~B}$ show larvae at 3,5 , and 8 days,

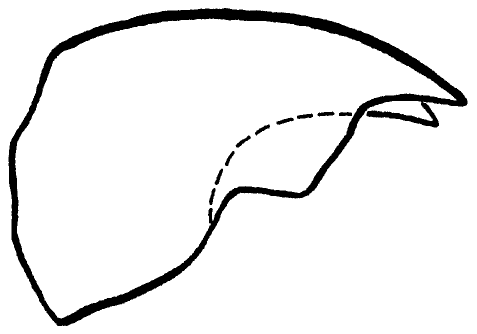

Fig. 4. Mandible of mature larva of A. azureus. 
respectively. The larva is attached to the spider while consuming the abdomen, but transfers its hold to the web or to nearby objects while consuming the remainder of the spider.

While the larva is small its host remains able to move and even run rapidly if seized by an appendage. Normally the spider does not move, but remains in the position in which it was left by the wasp. By the time the larva is half grown, the spider can no longer move and appears to be dead. A number of spiders were stung and left in the bottom of the cages; these spiders never resumed activity, though they could be stimulated to move.

The larva is able to consume the entire spider, though it does not always do so, as part of the spider may fall out of the web. The abdomen is consumed first, then the cephalothorax and legs. The older larva can be seen gnawing off bits of the spider, using welldeveloped mandibles. Parts of the spider appear to be deposited in a liquescent mass held in the ventral curve of the body (Fig. 5B), as is typical of many larval Pompilidae and Sphecidae. It is possible that some external digestion occurs within this glob of food.

A superficial examination of the larva shows some morphological divergence from the larvae of other pompilid species described by Evans (1959). The body is unusually smooth, lacking the prominent lobes and tubercles often found in other pompilids. The apex of the body is tapered and slightly flattened dorsoventrally, unlike any pompilid larvae described by Evans (1959), and may be a feature associated with hanging upside down by the tip of the abdomen. The mandibles are somewhat unusual in having a conspicuous dorsal medial angle (Fig. 4), but no ventral angle. They are totally unlike the edentate mandibles of Homonotus (illustrated by Evans 1959), a non-fossorial Old World genus that parasitized free-living spiders (Richards and Hamm 1939).

\section{Cocoon Construction and Emergence}

The cocoon of $A$. azureus (Fig. 4C) may be unique in the Order Hymenoptera. The entire surface of the cocoon is beset with long, erect hairs of uniform length. The larva begins by spinning a small net of silk at the posterior end of its body, using threads to attach this net to the surrounding web or substrate. The outer cocoon is then constructed as a loose net composed of loops. Each loop is a double strand of silk attached to the rim of the previously con- 


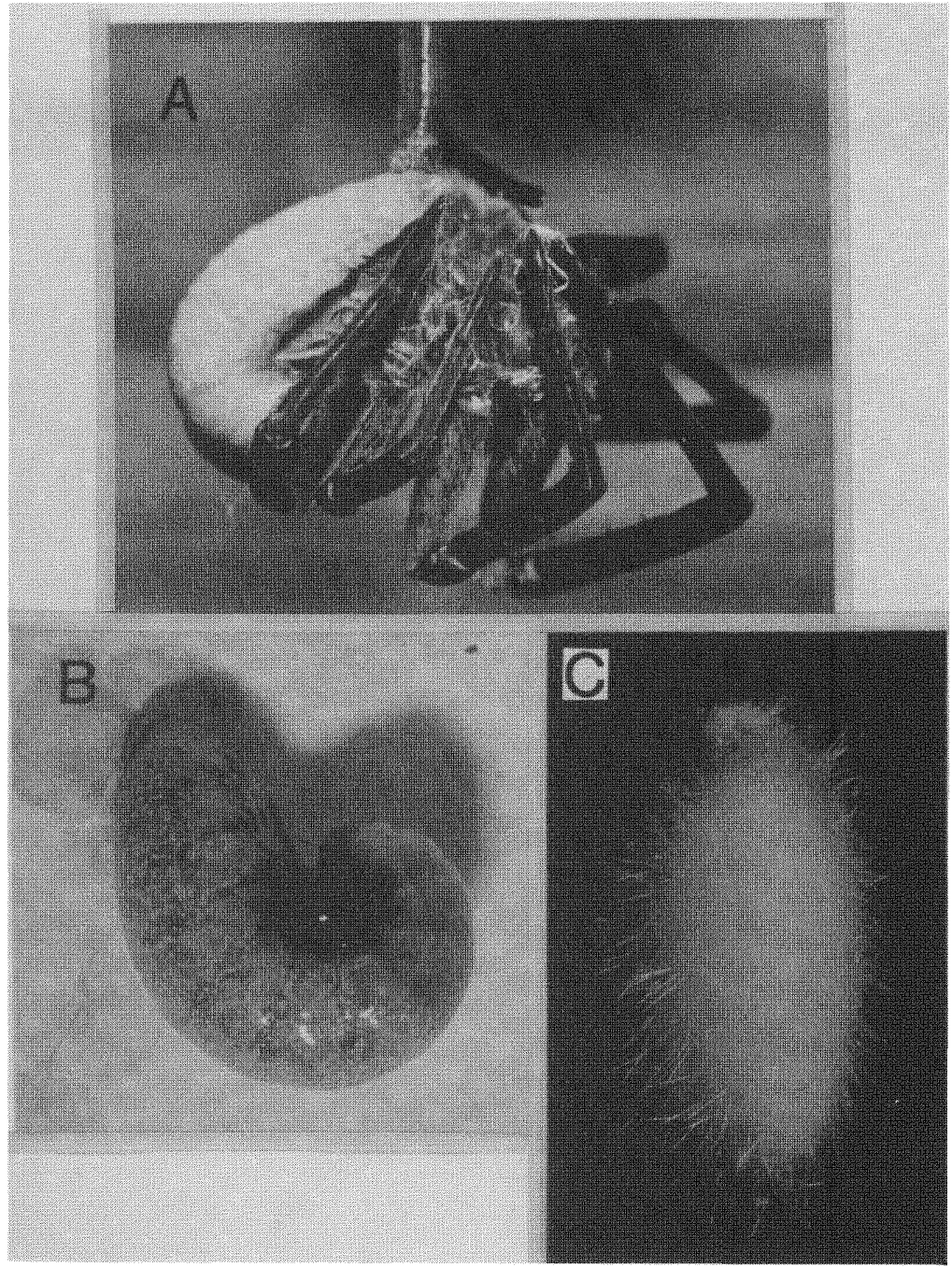

Fig. 5. Larva of A. azureus at 5 days (A) and 8 days (B); C, cocoon of $A$. azureus. 
structed section of cocoon. After completing a loop, the larva rears back its head drawing out two threads, then attenuates the threads, and breaks them with a movement of the head. The head is lowered and another loop initiated at the base of the hairs (Figs. 6A\&B). The larva works steadily with stereotypic motions. If disturbed, the larva draws its head into the finished part of the cocoon; when no longer alarmed, it raises its head, repeatedly touching the side of the cocoon until it reaches the rim, whereupon it begins to make loops and hairs as before. The shape of the outer cocoon is determined by the reach of the larva, and is larger and rounder than the finished cocoon. When the opaque inner cocoon is constructed, it draws together the outer cocoon to make it narrower and more compact. The larva requires about $\mathbf{4 8}$ hours to complete its cocoon.

The function of the hairs is unclear. They might lodge the cocoon even more securely in the web, but the numerous threads holding the posterior end of the cocoon in place appear adequate for this purpose. It seems likely that the hairs have a defensive function. It might be easier to guess the function of the hairs if we knew what potential enemies were present in natural habitats such as deep bark fissures and piles of rocks. Zatypota nigriceps (Walsh) is an ichneumonid with habits similar to those of $A$. azureus: it lives as an external parasitoid on spiders in their webs, and the cocoon is suspended in the web. The cocoon of this species is covered with erect loops (Townes and Townes 1960). We reared a larva of $Z$. crassipes Townes at the Archbold Biological Station; this specimen produced a cocoon covered with loops that were more or less appressed, but still provided a loose covering over the entire cocoon. The cocoons of both Allochares and Zatypotus are completely exposed to small parasitoids that could evade the strands of the spider web. It seems likely that the hairs and loops on these cocoons may offer some protection from small generalist parasitoids that attack exposed cocoons, such as the widespread pteromalid Dibrachys cavus (Walker). Studies of crop plants show that a dense pile of erect hairs is a general defense against sap sucking insects (Levin 1973) as well as some parasitoids and predators of these insects (Schuster and Calderon 1986). The same physical principles should apply to the cocoon of Allochares.

The color of $A$. azureus cocoons collected outdoors is medium to dark brown. The cocoons produced in the laboratory were white 

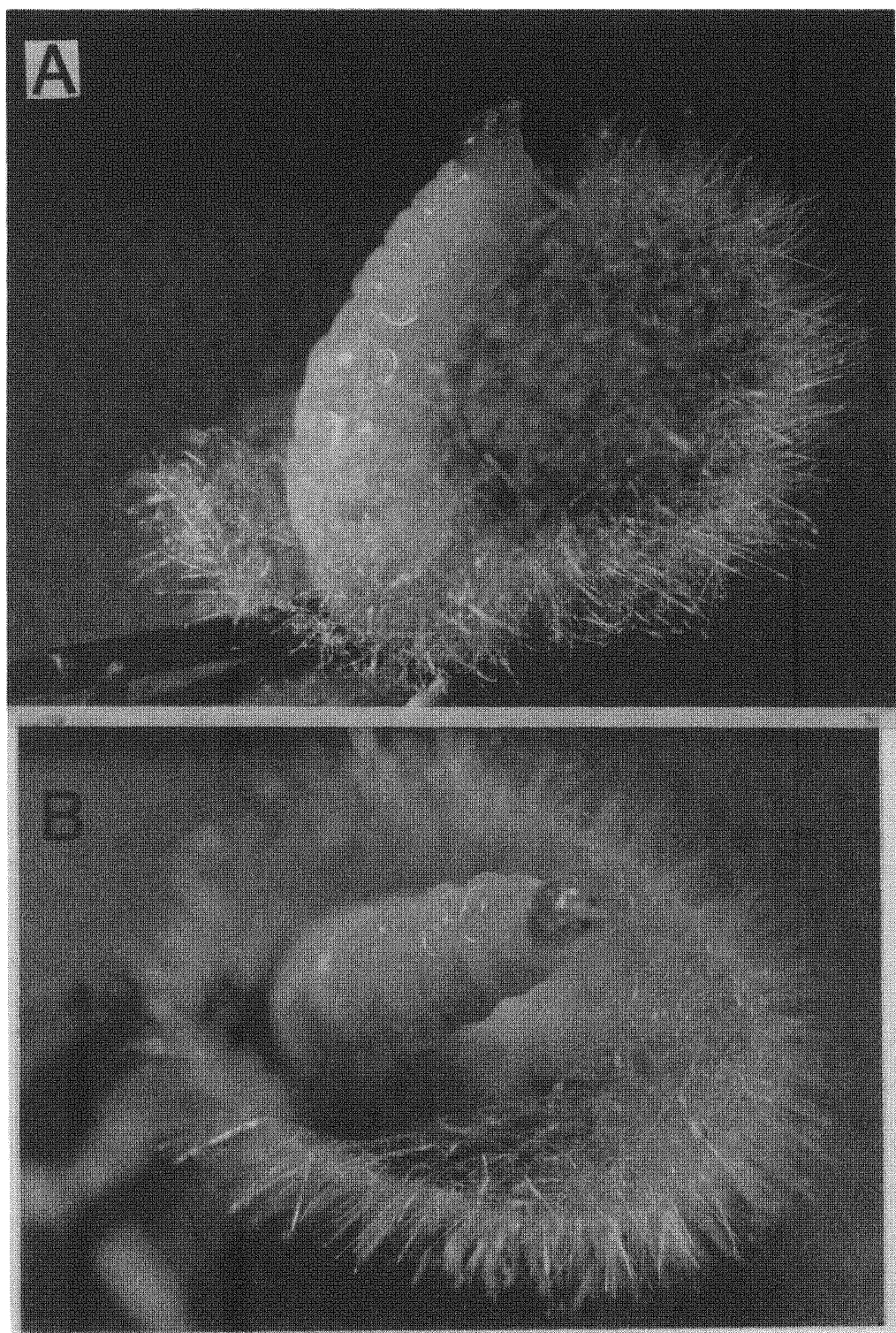

Fig. 6. A \& B, larva of $A$. azureus spinning outer cocoon. 
and remained that color. We eventually discovered that the white cocoons turned brown rapidly when placed in a saturated atmosphere. In natural situations the cocoons are likely to be exposed to high humidity, and we do not consider this color change to have any adaptive significance.

The adult emerges 35 to 60 days after cocoon formation, cutting a narrow slit almost encircling the anterior end of the cocoon. The cap usually remains attached to the cocoon after emergence.

\section{Mating}

Virgin females are willing to hunt and paralyze spiders, though they do not always oviposit. Eggs of virgin females appear to produce normal larvae, which develop into adult males. It appears that unmated females pass on their genes through production of at least a few male offspring, though it is not known whether unmated females are likely to occur in nature.

Virgin females placed outdoors attracted males; a total of 9 males were attracted to caged females. We have not seen males on the outside of the building where we placed the females, and it seems clear that the males are attracted by pheromones. When a male is caged with a virgin female, he runs rapidly about the cage. Upon encountering the female, he buzzes his wings a few times and attempts to climb on her back, without any noticeable courtship behavior. The male immediately extrudes his genitalia and attempts to mate. In our laboratory setup females seem reluctant to mate though the male may persist in his attempts for 15 minutes or more. If a spider is present in the cage, the female continues to hunt while the male is on her back. One female carried a paralyzed spider up the side of the cage, while apparently ignoring a male perched on her back attempting to mate. There were at least two successful matings in the laboratory, as shown by production of female offspring by lab-raised wasps.

A. azureus males are significantly smaller than females (males: $\mathrm{X}$ $=7.57 \mathrm{~mm}, \mathrm{SE}=.93, \mathrm{n}=7$; females: $\mathrm{X}=11.62 \mathrm{~mm}, \mathrm{SE}=1.78, \mathrm{n}=$ $10 ; \mathrm{t}=4.16, \mathrm{P}<.005$ ). In addition, Allochares size (cocoon length), irrespective of sex, is positively associated with spider weight $\left(\mathrm{r}^{2}=\right.$ $.917, \mathrm{n}=14, \mathrm{P}<.0001$ ). It seems probable that females tend to lay female eggs on larger spiders and male eggs on smaller spiders. Since spiders of all sizes are constantly available, sex ratios would 
not be excessively skewed by a tendency to lay male eggs on small hosts and female eggs on large hosts. Host size appears to be associated with sex of parasitoids in a number of families of wasps (Clausen 1939, Charnov 1982, Deyrup and Manley 1986).

\section{SeAsonal OCCURRENCE}

Specimens of $A$. azureus have been collected at the Archbold Biological Station from May to November, and Evans (1951) listed collections in the southeastern U.S. from April to December. There are probably several generations of wasps per year. The host spider may live several years, and all sizes of hosts are available through the year. There is no reason to suppose $A$. azureus shows any seasonality other than protracted or arrested development during cool weather.

\section{Discussion}

Allochares azureus differs structurally, ecologically, and behaviorally from all other pompilids that have been studied. The structural pecularities of the adult suggest two other genera of non-fossorial pompilids, the Old World Homonotus and the New World Notocyphus. Members of these genera paralyze and oviposit on free-living spiders, which recover from the effects of the sting and resume their normal activities. After the larva has fed for about a week, the spider dies (Williams 1928, Richards and Hamm 1942, Iwata 1942). The genus Minagenia may have similar habits, but has not been studied except for casual rearings (Kaston 1959). Numerous pompilids, including species of the tribe Aporini and some species of Pepsis, use the burrows of spiders as ready-made nests for the larvae (Evans 1953). A. azureus is apparently unique among pompilids in its use of the web for deposition of the spider and in having a larva that feeds and constructs its cocoon in the web. This is not to say that $A$. azureus occupies a previously unexploited adaptive zone, as members of the entire ichneumonid tribe Polysphinctini are very similar to $A$. azureus in larval habits (Townes and Townes 1960).

In its ecology $A$. azureus may resemble polysphinctine ichneumonids more than it does any pompilid, but $A$. azureus is not a particularly primitive species, nor even a specialized representative of a primitive offshoot of the Pompilidae. Evans (1953) points out 
that the other non-nesting pompilids are a phylogenetically diverse group of specialists that apparently have lost components of the typical pompilid behavioral repertoire. A. azureus would seem to fit this pattern perfectly. Although $A$. azureus may be ecologically similar to a polysphinctine ichneumonid, it is behaviorally much more complex in that it searches for the spider's abandoned web, transports prey, arranges the spider in the web in a special way, and prepares the prey for oviposition by removing a patch of hair.

The only other species of pompilid known to attack filistatid spiders is Pompilus (Perissopompilus) phoenix Evans (Evans 1966b). Members of the subgenus Perissopompilus are distinguished in part by unusually weakly spinose legs and absence of erect hairs on the body (Evans 1951). We suspect the loss of hairs and spines in Perissopompilus is convergent with Allochares and associated with the structure of the filistatid web.

\section{Conclusions}

Allochares azureus is a highly specialized parasitoid of Filistata hibernalis, and we would not expect it to attack unrelated spiders. The straight, thickened tarsal claws, the use of the web as a protected site for prey placement and oviposition, and the densely hairy cocoon all seem to be unique adaptations among the Pompilidae. $\boldsymbol{A}$. azureus appears to be a convenient pompilid for laboratory study. We hope our work will stimulate more intensive behavioral and ecological work on this highly unusual spider wasp.

\section{SUMMARY}

The mating, hunting, provisioning, ovipositional, and developmental behavior of the spider wasp Allochares azureus (Cresson) were studied under laboratory conditions at the Archbold Biological Station, Lake Placid, FL during 1987. The species preyed upon the domestic hackled band spider, Filistata hibernalis Hentz, during the warmer months of the year. The wasps flushed spiders from their silken retreats, stung them in the underside of the cephalothorax, causing instant paralysis, transported the spider into its web or another nearby, and entangled the prey in the web, using the forelegs. The wasp laid an egg on the spider's abdomen after depiling the hairs from the ovipositional area with the end of her abdomen. The larval wasp fed upon the spider while suspended in the 
web and then constructed a unique cocoon beset with long, erect hairs of uniform length. Morphological adaptations that may assist the wasp in hunting and prey entanglement are discussed. Key words: Allochares azureus, Filistata hibernalis, Pompilidae, Filistatidae, Parasitoid, Host-parasitoid interaction, Behavior, Adaptations

\section{ACKNOWLEDGMENTS}

We gratefully acknowledge Nancy Deyrup for the photographs used in this paper. We thank Glen Woolfenden (University of South Florida), Thomas Eisner (Cornell University), Shirley Denton, James Layne, Fred Lohrer, and James Wolfe (Archbold Biological Station) for reviewing the manuscript.

\section{Literature Cited}

Charnov, E. L. 1982. The theory of sex allocation. Princeton, N.J. Princeton University Press. $x+355$ pp.

Clausen, C. P. 1939. The effect of host size upon the sex ratio of hymenopterous parasites and its relation to methods of rearing and colonization, J. N.Y. Entomol. Soc. 47: 1-9.

Deyrup, M., and D. Manley. 1986. Sex-biased size variation in velvet ants (Hymenoptera: Mutillidae). Fla. Entomol. 69: 327-335.

Evans, H. E. 1951. A taxonomic study of the Nearctic spider wasps belonging to the tribe Pompilini (Hymenoptera: Pompilidae). Part III. Trans. Amer. Entomol. Soc. 77: 203-340.

Evans, H. E. 1953. Comparative ethology and the systematics of spider wasps. Syst. Zool. 2: 155-172.

Evans, H. E. 1959. The larvae of Pompilidae (Hymenoptera). Ann. Entomol. Soc. Amer. 52: 430-444.

Evans, H. E. 1966a. A revision of the Mexican and Central American spider wasps of the subfamily Pompilinae (Hymenoptera: Pompilidae). Mem. Amer. Entomol. Soc. 20: 1-442.

Evans, H. E. 1966b. Some unusual prey records for Pompilidae. Proc. Entomol. Soc. Wash. 60: 339.

Evans, H. E., AND C. M. Yoshimoto. 1962. The ecology and nesting behavior of the Pompilidae (Hymenoptera) of the northeastern United States. Misc. Pub. Entomol. Soc. Amer. 55: 5-15.

IwATA, K. 1942. Comparative studies on the habits of solitary wasps. Tenthredo 4: $1-146$.

KASTON, B. J. 1959. Notes on pompilid wasps that do not dig burrows to bury their spider prey. Bull. Brooklyn Entomol. Soc. 54: 103-113.

Levin, D. A. 1973. The role of trichomes in plant defense. Quart. Rev. Biol. 48: 3-15. 
Richards, O. W., and A. H. Hamm. 1939. The biology of the British Pompilidae (Hymenoptera). Trans. Soc. Brit. Entomol. 6: 51-114.

Schuster, M. F., AND M. CALDERon. 1986. Interactions of host plant resistant genotypes and beneficial insects in cotton ecosystems. Pp. 84-97 in Interactions of plant resistance and parasitoids and predators of insects. B. J. Boethel and R. D. Eikenbary, eds. Wiley \& Sons, 224 pp.

Townes, H., AND M. Townes. 1960. Ichneumon-flies of America north of Mexico: 2. Subfamilies Ephialtinae, Xoridinae, Acaenitinae. Bull. U.S. Nat. Mus. 216: 1-676.

Williams, F. X. 1928. Studies in tropical wasps-their hosts and associates (with descriptions of new species). Bull. Exp. Sta. Hawaiian Sugar Planter's Assoc. 19: 1-179. 

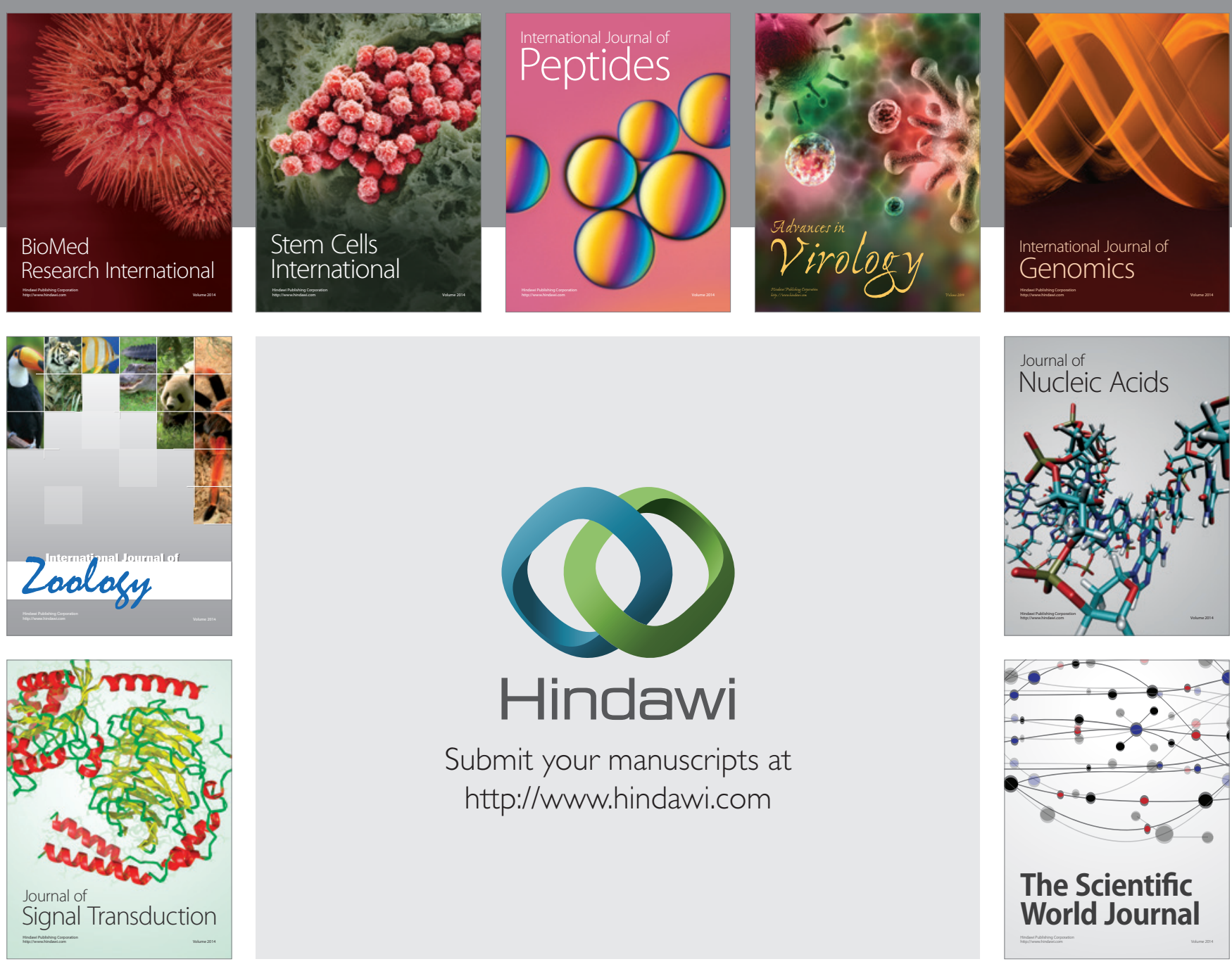

Submit your manuscripts at

http://www.hindawi.com
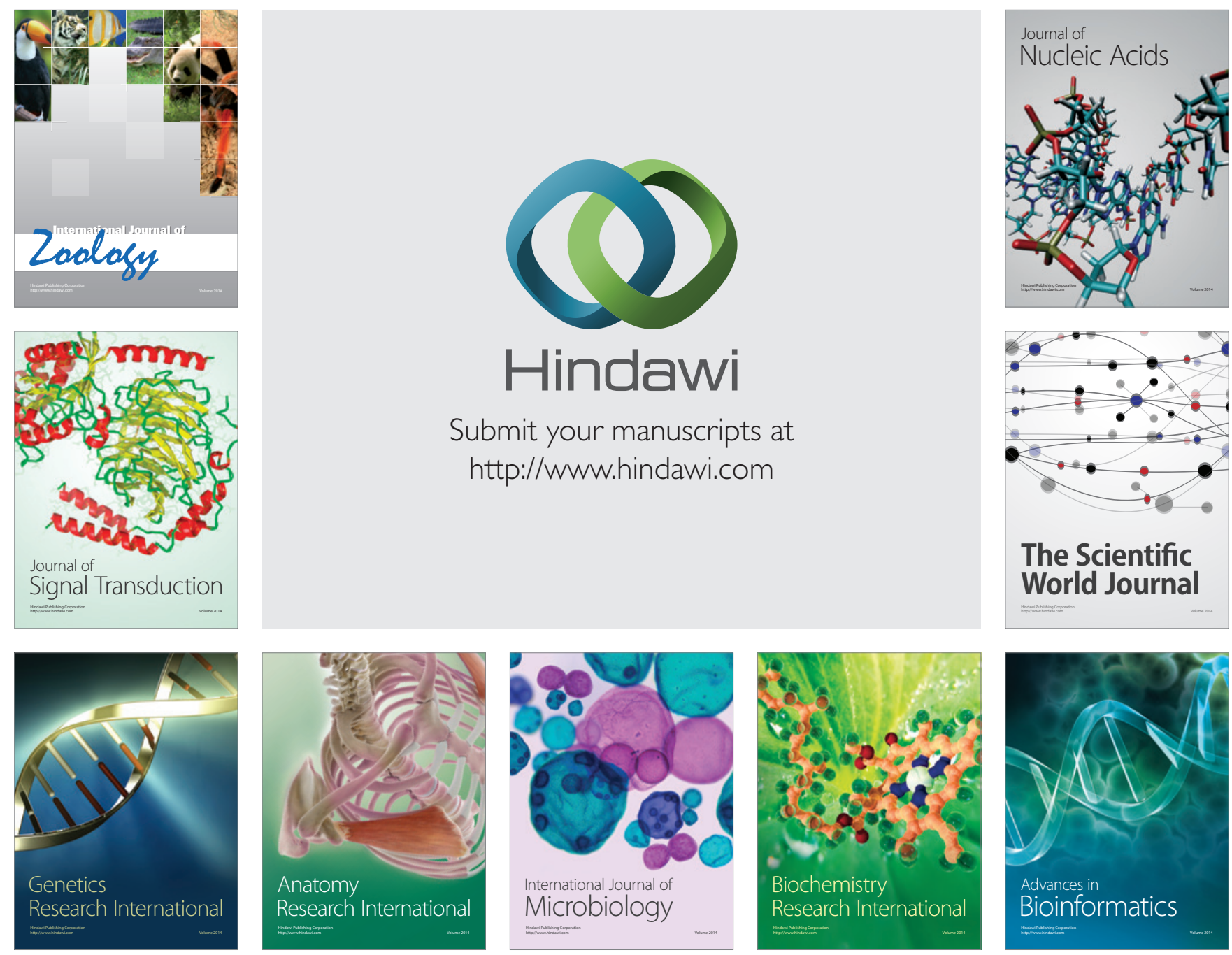

The Scientific World Journal
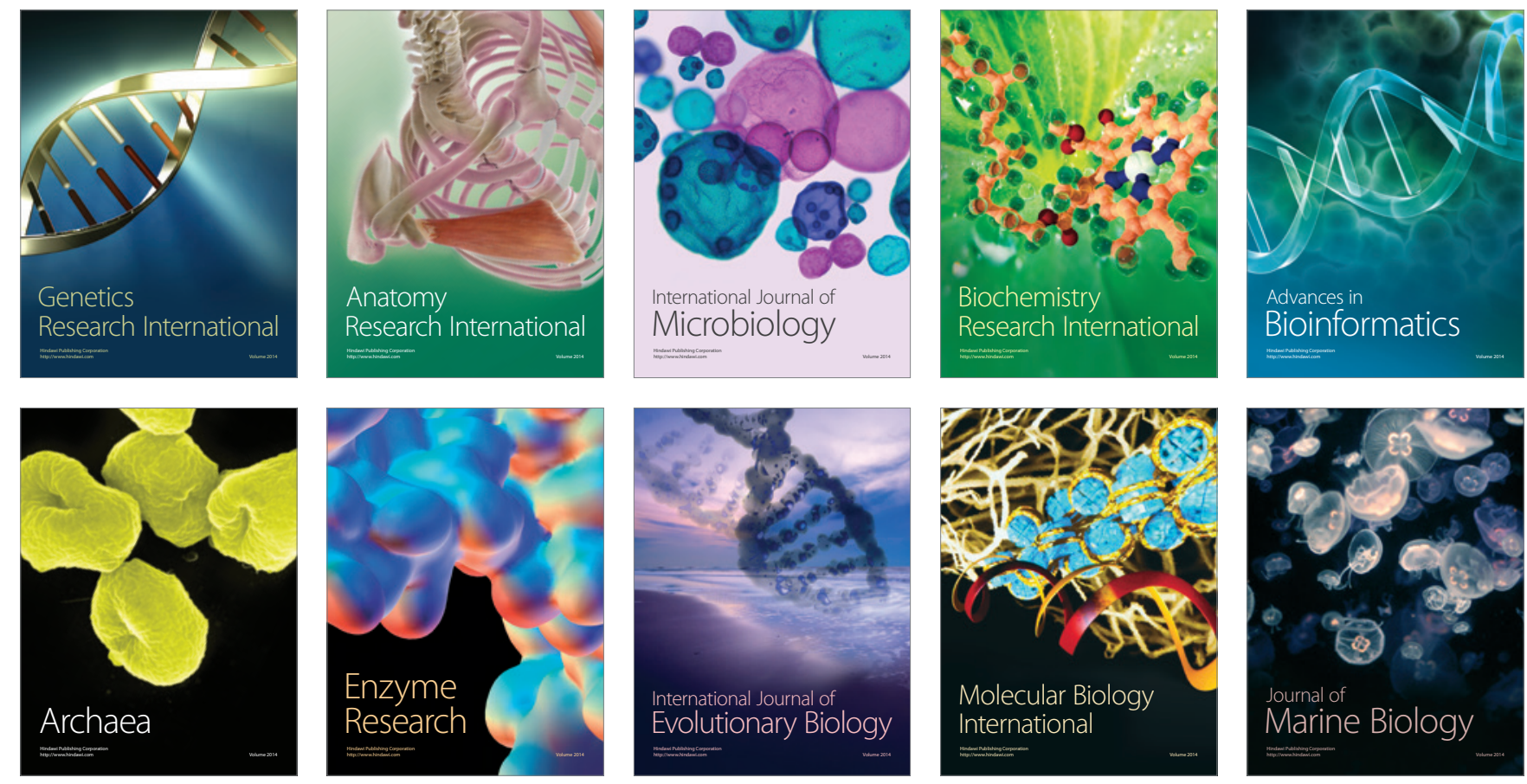